\title{
The prevalence of metabolic syndrome amongst patients with severe mental illness in the community in Hong Kong - a cross sectional study
}

Daniel T Bressington ${ }^{1 *}$, Jolene Mui ${ }^{2}$, Eric F C Cheung ${ }^{3}$, Joel Petch ${ }^{1}$, Allan B Clark ${ }^{4}$ and Richard Gray ${ }^{5}$

\begin{abstract}
Background: Patients with severe mental illness are at increased risk of developing metabolic disorders. The risk of metabolic syndrome in the Hong Kong general population is lower than that observed in western countries; however the prevalence of metabolic syndrome in patients with severe mental illness in Hong Kong is unknown.

Method: This cross-sectional study aimed to estimate the prevalence of metabolic syndrome in patients with severe mental illness in Hong Kong and to identify the relationships between metabolic syndrome and sociodemographic, clinical and lifestyle factors.

Results: A total of 139 patients with a diagnosis of severe mental illness participated in the study. The unadjusted prevalence of metabolic syndrome was 35\%. The relative risk of metabolic syndrome in comparison with the general Hong Kong population was 2.008 (95\% Cl 1.59-2.53, p < 0.001). In a logistic regression model sleep disruption and being prescribed first generation antipsychotics were significantly associated with the syndrome, whilst eating less than 3 portions of fruit/vegetables per day and being married were weakly associated.

Conclusion: The results demonstrate that metabolic syndrome is highly prevalent and that physical health inequalities in patients with severe mental illness in Hong Kong are similar to those observed in western countries. The results provide sufficient evidence to support the need for intervention studies in this setting and reinforce the requirement to conduct regular physical health checks for all patients with severe mental illness.
\end{abstract}

Keywords: Severe mental illness, Metabolic syndrome, Health behaviours, Physical health screening

\section{Background}

The physical health of patients with severe mental illness (SMI) in western societies has been shown to be extremely poor. It is estimated that patients with SMI have a life expectancy up to 25 years less than the general population [1] and that lifespan is worsening over time. Hong Kong has one of the highest life expectancies in the world [2]. To date there have been few empirical studies that provide estimates of whether physical health inequalities for patients in Hong Kong with SMI are similar to those observed in western countries.

\footnotetext{
* Correspondence: daniel.bressington@canterbury.ac.uk

${ }^{1}$ The Department of Health, Well-being and the Family, Canterbury Christ Church University, North Holmes Road, Canterbury, Kent CT1 1QU, UK Full list of author information is available at the end of the article
}

Studies in the UK and USA demonstrate that patients with SMI are more likely to develop cardiovascular disease and have a much higher rate of metabolic disorders than the general population [3]. A UK study [4] involving almost 800 SMI patients screened for physical health issues identified that $66 \%$ of patients had a Body Mass Index of over 25 and that risk factors for cardiovascular disease were very common. Metabolic syndrome (MES) is also commonly seen in patients with SMI; a study involving 689 participants in the USA [5] identified that males with schizophrenia were $138 \%$ more likely and females $251 \%$ more likely to have MES than the general population. MES is defined by the International Diabetes Federation as a collection of clinical indicators; including central obesity (measurable by waist circumference), hypertension

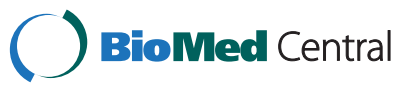


and altered lipid levels, amongst other clinical features. MES is reported to be a key risk factor for cardiovascular disease and diabetes mellitus both of which impact heavily upon life quality and expectancy [6].

To our knowledge the prevalence of metabolic syndrome in patients with SMI in Hong Kong has not been reported in the literature to date. However previous research has explored the prevalence in the general population, for example a study involving over 7,000 people estimated that the unadjusted prevalence of MES using the International Diabetes Federation (IDF) criteria was $17.6 \%$ [6]. An earlier smaller study [7] using the same IDF criteria estimated a prevalence rate of $7.4 \%$ in a Hong Kong working population. Findings reported by Thomas et al [8] reinforce the importance of identifying and treating MES in a Hong Kong setting as the syndrome was associated with an increased risk of cardiovascular disease (hazard ratio 6.39, 95\% CI 1.40-29.2) and increased all-cause mortality risk (hazard ratio $2.02,95 \%$ CI 1.02-4.00).

\section{Study aims}

The aims of this study are to:

- Estimate the prevalence of metabolic syndrome in community dwelling patients with SMI in Hong Kong;

- Identify the relationships between metabolic syndrome and socio-demographic, clinical, treatment and lifestyle factors in the study population.

\section{Methods}

\section{Study design}

This exploratory study uses a cross-sectional survey design to estimate the prevalence of MES in the sample population. We report an analysis of baseline data from the initial findings of a larger on-going prospective case series study. In order to ensure that the sample size obtained provided adequate statistical power we performed a power calculation. Based on the assumption that there are 800 patients with SMI registered with the CPN service, with a margin for error of $\pm 10 \%$ and a $95 \%$ confidence interval, we calculated that we would require a sample size of 86 participants.

\section{Recruitment and selection of participants}

30 Community Psychiatric Nurses (CPNs) working in the clinical setting screened and recruited participants. The study used a convenience sampling approach on a sequential basis, where each CPN asked the first five service users that they were routinely scheduled to visit and who met the inclusion criteria to participate in the study.

\section{Inclusion criteria}

- Male or female. Aged over 18; with a diagnosis of Severe Mental Illness (SMI) defined by a case-note diagnosis of any psychotic disorder (i.e. schizophrenia, schizoaffective disorder), bipolar affective disorder (type 1 or 2 ) or psychotic depression.

\section{Exclusion criteria}

- Any service user who did not have capacity to provide informed consent.

\section{Ethical considerations}

Ethical approval was obtained from the Hong Kong New Territories West Cluster Clinical and Research Ethics Committee. Participants were required to provide written informed consent in order to participate, the participant information sheets clearly stated that declining to take part would not negatively influence their clinical treatment. We chose to ask CPNs to recruit participants and collect data for a number of reasons. As recruitment and data collection was mainly carried out in the home environment we felt that it would be more appropriate for a CPN who knew the service users and their families well to carry out the examinations rather than an independent researcher. We also wanted to ensure that the CPNs would be immediately aware of any physical health concerns identified by the screening and hence recommend or provide clinical interventions as deemed appropriate.

\section{Data collection}

The Health Improvement Profile (HIP) [9] was used as a screening tool to collate data about the physical health state of individuals and their health-related behaviours. The community psychiatric nurses (CPNs) who collected data were trained how to use the HIP and carry out the required physical examinations shortly before the study commenced.

The HIP is a 27 item tool that is gender specific and is designed to be used as both a screening measure and a tool to facilitate interventions aimed to improve physical health and associated health behaviours [9]. Parameters are provided for each item in order that aspects of health and lifestyle can be flagged as red (indicating that an intervention is required) or green (no intervention recommended). The authors conducted literature reviews to establish the "normal" and "at risk" ranges and developed the tool through a series of pilot studies [10]. The utility and acceptability of the HIP as a screening tool was established in an exploratory case series [11]. In this study we analysed the health behaviours that our literature 
review revealed were most likely to be associated with metabolic syndrome.

The HIP was originally designed for use in a western population and therefore we modified the parameters of the HIP that relate to obesity to reflect the most recent guidelines for the assessment of MES in an Asian population. A BMI of 23 or over was used to represent being overweight and a waist circumference of $90 \mathrm{~cm}$ for males was used to determine central obesity. In line with recommendations from the International Diabetes Federation [12] we used the following criteria to determine MES in study participants: (Table 1).

In addition to the HIP data we also recorded a range of demographic and clinical characteristics: age, gender, education, marital status, diagnosis, duration of illness, employment status and prescribed medication. CPNs carried out basic physical examinations and data from blood tests were obtained from the servicer users' most recent outpatient medical records. All plasma glucose levels were obtained whilst participants were fasting.

\section{Data analysis}

Data were analysed using SPSS (version 17). We used the presence of MES as the dependent variable and conducted Chi-square tests or Fisher's exact tests to identify differences between demographic, clinical, treatment related and health behaviour variables in those with and without MES (in order that potential associations with MES could be highlighted). We also conducted independent samples T-tests for the continuous variables to determine differences in mean values for patients with and without MES. In a secondary analysis Chi-square tests were used to determine differences in cardiovascular risk factors according to gender.

In order to identify the independent risk factors associated with metabolic syndrome, the variables that are not part of the criteria for the syndrome were selected

Table 1 International diabetes federation criteria for metabolic syndrome in an Asian/Chinese population

Central obesity - defined by with ethnicity specific waist circumference of $\geq 80 \mathrm{~cm}$ (females) and $\geq 90 \mathrm{~cm}$ (males) plus any two of the following four factors:

\begin{tabular}{ll}
\hline Raised triglycerides & $\begin{array}{l}\geq 150 \mathrm{mg} / \mathrm{dL}(1.7 \mathrm{mmol} / \mathrm{L}) \\
\text { or specific treatment for this lipid abnormality }\end{array}$ \\
\hline $\begin{array}{l}\text { Reduced HDL } \\
\text { cholesterol }\end{array}$ & $<40 \mathrm{mg} / \mathrm{dL}(1.03 \mathrm{mmol} / \mathrm{L})$ in males \\
& $<50 \mathrm{mg} / \mathrm{dL}(1.29 \mathrm{mmol} / \mathrm{L})$ in females \\
& or specific treatment for this lipid abnormality \\
\hline $\begin{array}{l}\text { Raised blood } \\
\text { pressure }\end{array}$ & $\begin{array}{l}\text { Systolic } \mathrm{BP} \geq 130 \text { or diastolic } \mathrm{BP} \geq 85 \mathrm{~mm} \mathrm{Hg} \text { or } \\
\text { treatment of previously diagnosed hypertension }\end{array}$ \\
\hline $\begin{array}{l}\text { Raised fasting } \\
\text { plasma glucose }\end{array}$ & (FPG) $\geq 100 \mathrm{mg} / \mathrm{dL}$ (5.6 mmol/L), \\
\hline
\end{tabular}

(adapted from IDF; 2006) [12]. from a forward selection criterion by sequentially including variables in the logistic regression model until none were significant at the 0.2 level. We included variables in the final regression model that were significantly associated at the $\mathrm{p}<0.05$ level and also those weakly associated at the $\mathrm{p}<0.10$ level. In order to calculate the relative risk of developing MES in our sample we used data reported by Ko and Tang [6] for the prevalence in the general Hong Kong population.

\section{Results}

A total of 139 participants met the analysis criteria and had sufficient data recorded to estimate the prevalence of MES. Data were collected during February 2012.

\section{Demographic and clinical characteristics of study participants}

Table 2 details the demographic and illness characteristics of study participants.

Table 2 Demographic and clinical characteristics of participants

\begin{tabular}{lc}
\hline Demographic & Number (\%) \\
\hline Gender & $62(45)$ \\
Male & $77(55)$ \\
Female & \\
Marital Status & $93(67)$ \\
Single & $36(26)$ \\
Married & $8(6)$ \\
Widowed & $2(1)$ \\
Unknown & \\
Educational Level & $6(4)$ \\
None & $49(35)$ \\
Primary & $80(58)$ \\
Secondary & $4(3)$ \\
University/Post Graduate & \\
Diagnosis & $97(70)$ \\
Schizophrenia and related disorders & $14(10)$ \\
Bipolar Affective Disorder (BPAD) & $19(14)$ \\
Psychotic depression & $8(6)$ \\
Other (i.e. schizoaffective disorder; & \\
non-specified psychosis) & $1(<1)$ \\
Unknown & $33(24)$ \\
Employment Status & $32(23)$ \\
Unemployed & $4(3)$ \\
Employed & $2(1)$ \\
Homemaker & \\
Retired/other & \\
Unknown & \\
\hline & \\
\hline
\end{tabular}


The mean age of participants was 47 years $(\mathrm{sd}=11.1$, range 18-70). All patients were Hong Kong Chinese, the majority were female and two-thirds were single. Around half of participants were unemployed. In terms of educational level; a third had completed primary school, over half had completed secondary education and very few (3\%) had further/higher qualifications.

In terms of illness/treatment characteristics; almost three quarters of patients had a diagnosis of schizophrenia and related disorders, 19 (14\%) had psychotic depression and one in ten were diagnosed with bipolar affective disorder. On average they had been in contact with psychiatric services for $14(\mathrm{sd}=10.8)$ years.

Medications prescribed, individual prevalence of MES in each medication and their statistical association with MES are detailed in Table 3.

Over half of participants were prescribed second generation (atypical) antipsychotic medication, and just over a third was prescribed first generation (typical) antipsychotics. Around one in ten patients was being treated with clozapine. Around a quarter of service users were prescribed an antihypertensive, only $16(12 \%)$ were being offered diabetes treatments and very few $(n=6,4 \%)$ were prescribed a statin.

Table 3 Prescribed medication and association with MES

\begin{tabular}{lccc}
\hline $\begin{array}{l}\text { Prescribed first } \\
\text { generation } \\
\text { antipsychotics }\end{array}$ & $\begin{array}{c}\text { Number } \\
\text { (\%) }\end{array}$ & $\begin{array}{c}\text { Number of patients } \\
\text { with MES (\%) }\end{array}$ & $x^{2}$, P-value \\
\hline Yes & $51(37)$ & $25(49)$ & $X^{2}=6.69, p=0.01$ \\
No & $88(63)$ & $24(27)$ &
\end{tabular}

\section{Prescribed Second Generation Antipsychotics}

$\begin{array}{llll}\text { Yes } & 81(58) & 26(32) & \text { NS } \\ \text { No } & 58(42) & 23(39) & \end{array}$

\section{Prescribed Clozapine}

$\begin{array}{lll}\text { Yes } & 16(12) & 5(31) \\ \text { No } & 123(89) & 44(36)\end{array}$

Prescribed Long Acting Antipsychotic Injection

$\begin{array}{llll}\text { Yes } & 33(24) & 14(42) & \text { NS } \\ \text { No } & 106(76) & 35(33) & \end{array}$

Prescribed an antihypertensive

$\begin{array}{lll}\text { Yes } & 32(23) & 18(56) \\ \text { No } & 107(77) & 31(29)\end{array} \quad x^{2}=8.03, p<0.01$

Prescribed a statin

\begin{tabular}{lccc} 
Yes & $6(4)$ & $6(100)$ & $x^{2}=11.52, p<0.01$ \\
No & $133(96)$ & $43(32)$ & \\
Prescribed diabetes treatment & & \\
Yes & $16(12)$ & $12(75)$ & $x^{2}=12.52, p<0.01$ \\
No & $123(89)$ & $37(30)$ & \\
\hline
\end{tabular}

$\mathrm{P}$ for association between prescribed medications and metabolic syndrome, tested by $X^{2}$ test.

NS $=$ Not significant.
Prevalence of MES and other cardiovascular risk factors

The prevalence, relative risk of MES and cardiovascular risk indicators split according to gender are shown in Table 4.

The unadjusted prevalence of MES in the entire sample was just over a third $(35 \%, n=49)$. When data are split according to gender; $31 \%(n=19)$ of males and $39 \%$ (30) females met the diagnostic criteria for MES. The vast majority of patients $(80 \%, n=111)$ had a BMI of 23 or over.

Around a quarter of participants $(24 \%, \mathrm{n}=33)$ were reported to be hypertensive, raised triglycerides were observed in 34 (25\%) of service users and 32 (23\%) were found to have reduced levels of HDL cholesterol. Raised fasting plasma glucose levels were detected in 17 (12\%) of patients.

In comparison with males a higher percentage of women were observed to be overweight, however Chi-square tests demonstrate that the only cardiovascular risk factor that is significantly more likely in women is a waist circumference over recommended limits $\left(\chi^{2}=11.40, \mathrm{p}=0.001\right)$.

\section{Health behaviours of study participants}

The self-reported health behaviours of participants and associations with MES are shown in Table 5. Very few participants used cannabis $(n=3,2 \%)$ or drank more than 4 units of alcohol per day $(n=7,5 \%)$, similarly few participants consumed more than $600 \mathrm{mg}$ of caffeine each day $(n=8,6 \%)$ and $38(27 \%)$ smoked tobacco. The majority of patients $(n=86,62 \%)$ exercised for less than recommended levels (30 minutes per day five times per week) and around a fifth ate more than 3 portions of fat per day $(n=27,19 \%)$ and $26(19 \%)$ consumed less than three portions of fruit/vegetables per day.

\section{Associations with MES \\ Demographic and clinical characteristics}

None of the demographic or clinical characteristics were found to be significantly associated with MES in this group of patients. However, independent sample T-tests demonstrate that there is a trend towards the mean duration of illness being longer in the group of patients with metabolic syndrome $(t=1.94, \mathrm{df}=137, \mathrm{p}=0.054)$.

\section{Treatment-related variables}

There were significant relationships observed between MES and medical treatments for associated issues; diabetes treatments $\left(\chi^{2}=12.52, \mathrm{p}<.001\right)$, statins $\left(\chi^{2}=11.52\right.$, $\mathrm{p}<.001)$ and antihypertensives $\left(\chi^{2}=8.03, \mathrm{p}<.01\right)$ were all strongly associated with MES. As these variables constitute elements of the criteria for MES this result was expected and therefore the associations are not particularly clinically relevant. 
Table 4 Prevalence of MES (with relative risk) and indicators of cardiovascular risk (split according to gender)

\begin{tabular}{|c|c|c|c|c|}
\hline & Male $\mathrm{n}=62,(\%)$ & Female $\mathrm{n}=77,(\%)$ & Total n, (\%) & $x^{2}$, P-value ${ }^{*}$ \\
\hline Metabolic Syndrome present & $19(31)$ & $30(39)$ & $49(35)$ & NS \\
\hline $\begin{array}{l}\text { Relative Risk of Metabolic Syndrome } \\
(95 \% \mathrm{Cl}, \mathrm{P} \text { value })^{* *}\end{array}$ & $\begin{array}{l}1.737(1.18-2.54 \\
p<0.01)\end{array}$ & $\begin{array}{l}2.230(1.67-2.97 \\
p<0.01)\end{array}$ & $\begin{array}{l}2.008(1.59-2.53 \\
p<0.01)\end{array}$ & \\
\hline BMI overweight- Hong Kong criterion $(\geq 23)$ & $48(77)$ & $63(82)$ & $111(80)$ & NS \\
\hline BMI overweight- International criterion ( $\geq 25)$ & $34(55)$ & $45(58)$ & $79(57)$ & NS \\
\hline $\begin{array}{l}\text { Waist Circumference (males } \geq 90 \mathrm{~cm} \text {, } \\
\text { females } \geq 80 \mathrm{~cm} \text { ) }\end{array}$ & $20(32)$ & $47(61)$ & $67(48)$ & $\begin{array}{l}x^{2}=11.40 \\
p<0.01\end{array}$ \\
\hline Hypertension - Blood pressure $\geq 140 / 90$ & $12(19)$ & $21(27)$ & $33(24)$ & NS \\
\hline Hypercholesterolemia - Total Cholesterol $\geq 6.2 \mathrm{mmol} / \mathrm{L}$ & $15(24)$ & $16(21)$ & $31(22)$ & NS \\
\hline Raised LDL cholesterol - LDL $\geq 4.1 \mathrm{mmol} / \mathrm{L}$ & $11(18)$ & $12(16)$ & $23(16)$ & NS \\
\hline $\begin{array}{l}\text { Reduced HDL cholesterol }-\mathrm{HDL}<1.00 \mathrm{mmol} / \mathrm{L} \\
\text { (males), }<1.30 \mathrm{mmol} / \mathrm{L} \text { (females) }\end{array}$ & $13(21)$ & $19(25)$ & $32(23)$ & NS \\
\hline Raised fasting plasma glucose $-\geq 7.00 \mathrm{mmol} / \mathrm{L}$ & $8(13)$ & $9(12)$ & $17(12)$ & NS \\
\hline Raised triglycerides - $\geq 2.2 \mathrm{mmol} / \mathrm{L}$ & $17(27)$ & $17(22)$ & $34(25)$ & NS \\
\hline
\end{tabular}

*P for significant differences in cardiovascular risk according to gender, tested by $\mathrm{X}^{2}$ test.

NS = not statistically significant.

** Data reported by Ko and Tang [6] for the prevalence of MES in the general Hong Kong population was used to calculate the relative risk in this sample.

In terms of medicines prescribed for mental health, only 1 st generation antipsychotics were significantly associated with MES $\left(\chi^{2}=6.69, \mathrm{p}<.01\right)$. Surprisingly there was no relationship observed between numbers of antipsychotics prescribed, clozapine or atypical antipsychotics and MES.

\section{Health behaviour related variables}

Of all the health-behaviour related variables only sleep disruption ( $<3$ hours or $>8$ hours per night) was associated with $\operatorname{MES}\left(\chi^{2}=4.64, \mathrm{p}=0.031\right)$. A secondary analysis further demonstrated that when all the health behaviour variables are grouped together as one risk factor they were not significantly associated with MES.

Table 5 Health behaviours of participants

\begin{tabular}{lcc}
\hline Health behaviour & $\begin{array}{c}\text { Total } \mathbf{n}, \\
(\%)\end{array}$ & $\boldsymbol{x}^{2}$, P-value \\
\hline Smoking status (smoker/passive smoker) & $38,(27)$ & NS \\
Alcohol intake ( $>4$ units daily) & $7,(5)$ & NS \\
$\begin{array}{l}\text { Exercise (<30 minutes a day for } \\
5 \text { days per week) }\end{array}$ & $86,(62)$ & NS \\
$\begin{array}{l}\text { Diet fruit and vegetables } \\
\text { ( } 2 \text { daily portions) }\end{array}$ & $26,(19)$ & NS \\
$\begin{array}{l}\text { Diet Fats ( } \geq 3 \text { portions per day) } \\
\text { Fluid Intake (<1 L or }>3 \text { L per day) }\end{array}$ & $27,(19)$ & NS \\
Caffeine Intake ( $\geq 600$ mg/day) & $8,(6)$ & NS \\
Disrupted sleep ( $>8$ h or $<3$ h) & $38,(27)$ & $x^{2}=4.64, p<0.05$ \\
Cannabis use (occasional or regular) & $3,(2)$ & NS \\
\hline
\end{tabular}

$\mathrm{P}$ for association between health behaviour and metabolic syndrome, tested by $\mathrm{X}^{2}$ test.

$N S=$ Not statistically significant.

\section{Independent related variables}

Table 6 shows the adjusted odds ratios for independent risk factor variables which were significant at the 0.2 level in the regression model. In the logistic regression model sleep disruption (OR 3.57 (95\% CI 1.45, 8.79), $\mathrm{p}=0.006$ ), being prescribed first generation antipsychotics (OR 3.83 (95\% CI 1.63, 9.04), $\mathrm{p}=0.002$ ) were significant risk factors for MES. The model also shows that eating less than 3 portions of fruit/vegetables per day (OR 2.19 (95\% CI 0.86,5.59), $\mathrm{p}=0.099$ ) and being married (OR 0.45 (95\% CI $0.19,1.09), \mathrm{p}=0.077$ ) were weakly significant risk factors.

\section{Discussion}

Metabolic syndrome is highly prevalent in this cohort of patients; $35 \%$ of the participants (31\% of men and 39\% of women) met the IDF criterion. Previous studies show that the prevalence of MES in patients with SMI differs in accordance with the population being studied. Research carried out in the USA has estimated the prevalence of MES in SMI to be between 28.7\% [13] and 60\% [14]. A similarly high prevalence rate of $54 \%$ was reported in an Australian study [15]. Whilst a Canadian study calculated

Table 6 Adjusted odds ratios for the presence of metabolic syndrome

\begin{tabular}{lcc}
\hline Factor & Odds ratio (95\% Cl) & p-value \\
\hline First generation antipsychotics & $3.83(1.63,9.04)$ & 0.002 \\
Disrupted sleep (>8 h or $<3$ h) & $3.57(1.45,8.79)$ & 0.006 \\
Marital status (single/widowed/ & $0.45(0.19,1.09)$ & 0.077 \\
divorced vs. married) & & \\
Diet fruit and vegetables & $2.19(0.86,5.59)$ & 0.099 \\
\hline
\end{tabular}


a prevalence rate of $44.7 \%$ [16] and a Finnish project [17] estimated $37.1 \%$. Studies that explore Asian populations tend to report lower rates of MES in SMI than western countries, for example Littrell et al [18] report that $22 \%$ of patients with schizophrenia in Taiwan had MES, whilst in Thailand Srissurapanont et al [19] estimated a prevalence rate of $20 \%$. Although direct comparisons with other countries are complicated by the differing prevalence rates in the general populations, our results suggest that the rates of MES in patients with SMI in Hong Kong are likely to be lower than those observed in western populations and higher than in some other Asian countries.

It is perhaps more clinically relevant to report the increased risk of MES in SMI with the general population (please see Table 4). In the general Hong Kong community the unadjusted prevalence rates of MES have been reported as $17.6 \%$ (17.7\% of males and $17.5 \%$ of females) [6]. As our results indicate that $35 \%$ of patients with SMI have MES (31\% men and 39\% women) the relative risk of metabolic syndrome in comparison with the general Hong Kong population is 2.008 (95\% CI 1.59-2.53, $\mathrm{p}<0.001)$. The relative risk for males is 1.737 ( $95 \%$ CI 1.18-2.54, $\mathrm{p}=0.005$ ) and for females is 2.230 (95\% CI 1.67-2.97, p<0.001). McEvoy et al., [5] estimate the increased risk of MES in SMI to be $138 \%$ for men and $251 \%$ for women in the USA. Therefore, although the overall rates of MES in patients with SMI in Hong Kong are lower than in some western countries the increased risk is potentially higher for men, although slightly lower for women, compared to rates reported in the USA.

Despite the high prevalence of MES observed in this study few patients were prescribed medical treatments for dyslipidaemia or diabetes. McEvoy et al., [5] reported similar findings in the USA; significant percentages of SMI patients with these conditions were not receiving treatment. This finding suggests the requirement for enhanced collaborative working between primary care and specialist mental health services, in order that patients can receive prompt appropriate medical treatments once such conditions are identified.

None of the demographic or clinical characteristics were found to be significantly associated with MES in our initial bivariate analysis. However, the relationship between duration of illness and MES was found to be approaching statistical significance. The prevalence of MES in women was higher than in men, but the difference was not significant $\left(\chi^{2}=1.04, \mathrm{p}=0.31\right)$. These findings are consistent with results reported by John et al., [15] however many other studies identify a clear link between age, gender, duration of psychiatric illness and MES [19,20].

The multivariable logistic regression model highlights that patients in this study who were married were slightly more likely to have developed MES than those who were single/divorced or widowed (OR 0.45 (95\% CI
0.19,1.09), $\mathrm{p}=0.077$ ). Previous studies that explore the relationship between marital status and MES have reported equivocal results, for example married women in the general population of USA were found to have a lower prevalence of MES than those who were single [21] whilst no such relationships were observed in a study of over 2000 patients in Taiwan [22]. One possible explanation for our result is an inter-relationship between MES, marriage and diet.

Previous authors [23] have proposed that that the unhealthy lifestyles of patients with SMI contribute towards the aetiology of MES. Unexpectedly in the bivariate analysis we did not identify any significant associations between lifestyle variables (other than sleep) and MES in this sample. However, eating less than recommended levels of fruits and vegetables was found to be a weak predictor of MES in the final multivariate regression model. The relationship between poor diet and MES in people with SMI has been reported in many studies i.e. [24]; these previous results and our observations suggest that health promotion approaches aimed at reducing cardiovascular risk need to consider incorporating dietary interventions.

The association between sleep disruption and MES was significant, and the regression model also identified sleep disruption as being a risk factor for the syndrome. This finding has previously been reported by a number of authors, for example; Hall et al [25] conducted a study of over 200 participants in the general population in the USA and concluded that there is an increased risk of developing MES of $45 \%$ in people who sleep more or less than 7-8 hours per day. The association between short sleep duration and MES may be explained by the relationship identified between obstructive sleep apnoea and many indicators of MES, for example; obesity, hypertension, diabetes and dyslipidaemia [26]. The evidence relating to an association between a long duration of sleep and MES is less clear; however some authors conclude that risk factors for MES are more common in long sleepers, i.e. type 2 diabetes [25]. The relationship between excess sleep and MES observed in our study may also be explained by the likelihood that some of the more sedating antipsychotic drugs have been observed to be implicated in the development of MES [27], or potentially that those participants with sleep disruption may be more likely to be engaging in a generally more sedentary lifestyle.

First generation (or typical) antipsychotics were observed to have an association with MES and were also significant in our regression model, a surprising finding given that many studies demonstrate that second generation antipsychotics are more likely to be associated with MES than first generation drugs [27]. However, our findings are supported by a number of studies that identify the same association 
$[15,17,28]$. One potential explanation for this result is that we did not perform analysis for the association of individual atypical antipsychotic preparations with MES (other than clozapine), and this may be a confounder as some atypical antipsychotics have been reported to be more likely to cause weight gain than others [27]. Nor did we collect data relating to the extent of adherence with antipsychotic medications. It is therefore not possible to draw firm conclusions about the potential impact of these medications on physical health.

In the literature there is continued debate about the likelihood of atypical antipsychotics being involved in the aetiology of MES [15]. The current physical health policy in the clinical setting in which our research was carried out recommends that patients receiving atypical (or second generation) antipsychotics require at least yearly screening for metabolic abnormalities; our results suggest that this should be extended to anyone with a diagnosis of a severe mental illness irrespective of the type of antipsychotic prescribed. Although the mean duration of illness in those with MES was not significantly different to those without MES, the observed trend and previous research suggests that a longer duration of illness may increase the risk of MES. This may also provide a potential explanation of why typical antipsychotics are associated with MES in this study; current treatment guidelines recommend the use of atypicals for patients newly diagnosed and therefore it is likely that those who are taking typical medications have been established on these for some time and subsequently may have a longer duration of illness.

There are a number of study limitations that could have influenced our findings and which also make it difficult to generalise the results to other countries or the wider eastern world. This study has a cross-sectional design, includes a relatively small number of patients with SMI and uses a convenience sampling approach rather than utilising an epidemiological sampling strategy. The small numbers of participants may account for the lack of statistical associations observed between MES and the independent variables. Recruitment bias is possible because participants were invited to take part by their clinicians on a sequential basis. Blood test results were obtained from recent data recorded in out-patient case notes; it is possible that service users whom have attended for tests may have been invited due to concerns about their physical health and therefore be at a relatively higher risk of MES than those patients with SMI who have not had blood tests recorded recently.

Although this study has a relatively small number of participants, the findings provide sufficient evidence to support the need for intervention studies in this setting and reinforce the requirement to conduct regular MES screening. Future research in Hong Kong should also aim to establish the prevalence of MES in patients with SMI using a larger sample size and a randomised epidemiological sampling strategy.

\section{Conclusion}

The results demonstrate that physical health inequalities in patients with severe mental illness in Hong Kong are similar to those observed in western countries. MES was found to highly prevalent in this population as $35 \%$ of the participants (31\% men and 39\% women) met the IDF diagnostic criteria. The relative risk of metabolic syndrome in this cohort in comparison to the general Hong Kong population is 2.008 (1.737 for males and 2.230 for females). In this study being prescribed first generation antipsychotics and sleep disruption are significant risk factors for MES, whilst eating less than recommended levels of fruits/vegetables and being married are weakly associated with the syndrome. The findings therefore suggest that clinicians in Hong Kong should conduct regular physical health screening for MES irrespective of the type of antipsychotic prescribed, ensure that patients with identified physical comorbidities receive medical treatment promptly and increase the focus of clinical interventions towards physical health promotion strategies.

\section{Competing interests}

Professor Richard Gray has received honoraria and provided consultancy to AstraZeneca, Bristol-Myers Squibb, Jannsen Cilag, Eli Lilly and Co. Otsuka Pharmceutical Europe Ltd, Pfizer, received honoraria from AstraZeneca, BristolMyers Squibb, Jannsen Cilag, Eli Lilly and Co. Otsuka Pharmceutical Europe Ltd, Lunbeck, Pfizer, Wyeth and had research funding from AstraZeneca, the Medical Research Council, the National Institute for Mental Health, the Department of Health, Comic Relief. Dan Bressington has received honorarium payments for educational consultancy from Bristol-Myers Squibb, Lundbeck and Jannsen-Cilag. The other authors declare no potential conflicts of interest. This study was not funded by any external body.

\section{Authors' contributions}

DB was the project lead, designed the study, contributed towards data input, jointly analysed data, interpreted the data analysis and was lead for the writing of the article. JM was the lead for data collection, contributed towards the study design and commented on the final paper. R G provided advice on study design, delivered the training, advised on data analysis and contributed towards the final paper. EC provided advice on study design, advised on data analysis/interpretation and contributed towards the final paper. JP jointly input data, helped interpret the data analysis and contributed towards writing the final paper. AC provided advice on the data analysis strategy, jointly analysed data and contributed towards the final paper. All authors read and approved the final manuscript.

\section{Author details}

${ }^{1}$ The Department of Health, Well-being and the Family, Canterbury Christ Church University, North Holmes Road, Canterbury, Kent CT1 1QU, UK. ${ }^{2}$ Community Psychiatric Service, Castle Peak Hospital, 15 Tsing Chung Koon Road, Tuen Mun, New Territories, Hong Kong. ${ }^{3}$ Castle Peak Hospital, 15 Tsing Chung Koon Road, Tuen Mun, New Territories, Hong Kong. ${ }^{4}$ Norwich Medical School, University of East Anglia, Norwich NR4 7TJ, UK. ${ }^{5}$ University of the West of England, Frenchay Campus, Coldharbour Lane, Bristol, BS16 1QY, UK. 


\section{References}

1. Colton CW, Manderscheid RW: Congruencies in increased mortality rates, years of potential life lost, and causes of death among public mental health clients in eight states. Prev Chronic Dis 2006, 3:1-14.

2. Law, Yip: Healthy life expectancy in Hong Kong special administrative region of China. Bull World Health Organ 2003, 81:43-47.

3. Brown S, Inskipp H, Baroclough B: Causes of excess mortality of schizophrenia. Br J Psychiatry 2000, 177:212-217.

4. Eldridge D, Dawber N, Gray R: A well-being support program for patients with severe mental illness: a service evaluation. BMC Psychiatry 2011, 11:46. doi:10.1186/1471-244X-11-46.

5. McEvoy P, Meyer J, Goff D, Nasrallah H, Davis S, Sullivan L, Meltzer H, Hsiao J, Stroup S, Lieberman J: Prevalence of the metabolic syndrome in patients with schizophrenia: baseline results from the Clinical Antipsychotic Trials of Intervention Effectiveness (CATIE) schizophrenia trial and comparison with national estimates from NHANES III. Schizophr Res 2005, 80:19-32.

6. Ko G, Tang J: Metabolic syndrome in the Hong Kong community: the United Christian Nethersole Community Health Service primary healthcare programme 2001-2002. Singapore Med J 2007, 48(12):1111-1116.

7. Ko G, Cockram C, Chow C, Yeung V, Chan W, So W, Chan N, Chan J: Metabolic syndrome by the international diabetes federation definition in Hong Kong Chinese. Diabetes Res Clin Pract 2006, 73:58-64.

8. Thomas GN, Schooling CM, McGhee SM, Ho DSY, Cheung BMY, Wat NMS, Janus ED, Lam KSL, Lam TH: Metabolic syndrome increases all-cause and vascular mortality: the Hong Kong cardiovascular risk factor study. Clin Endocrinol 2007, 66(5):666-671.

9. White J, Gray R, Jones M: The development of the serious mental illness physical Health Improvement Profile. J Psychiatr Ment Heal Nurs 2009, 16:493-498.

10. White J, et al: The serious mental illness health improvement profile [HIP]: study protocol for a cluster randomised controlled trial. Trials 2011, 12:167. doi:10.1186/1745-6215-12-167.

11. Shuel F, White J, Jones M, Gray R: Using the serious mental illness health improvement profile [HIP] to identify physical problems in a cohort of community patients: a pragmatic case series evaluation. Int I Nurs Stud 2010, 47(2):136-145.

12. International Diabetes Federation consensus workshop: The IDF consensus worldwide definition of the METABOLIC SYNDROME. International Diabetes Federation; 2006. available at: [http://www.idf.org/webdata/docs/ IDF_Meta_def_final.pdf].

13. Straker DA, Rubens E, Koshy F, Kramer E, Manu P: The prevalence of the metabolic syndrome among patients treated with atypical antipsychotic. San Francisco: Abstract Presented at the American Psychiatric Association Annual Meeting; 2003.

14. Kato MM, Currier MB, Gómez CM, Hall L, González-Blanco M: Prevalence of metabolic syndrome in Hispanic and non-Hispanic patients with schizophrenia. Prim. Care Companion; J Clin Psychiatry 2004, 6:74-77.

15. John A, Koloth R, Dragovic M, Lim S: Prevalence of metabolic syndrome among Australians with severe mental illness. Med J Aust 2009, 190(4):176-179.

16. Cohn T, Prud'homme D, Streiner D, Kameh H, Remington G: Characterizing coronary heart disease risk in chronic schizophrenia: high prevalence of the metabolic syndrome. Can J Psychiatry 2004, 49:753-760.

17. Heiskanen T, Niskanen L, Lyytikainen R, Saarinen PI, Hintikka J: Metabolic syndrome in patients with schizophrenia. J Clin Psychiatry 2003, 64:575-579.

18. Littrell KH, Petty R, Ortega TR, Moore D, Ballard A, Clough R, Lan T-S, Selby C: Insulin resistance and syndrome $X$ among patients with schizophrenia. San Francisco: Abstract Presented at the American Psychiatric Association Annual Meeting; 2003.

19. Srisurapanont $M$, Likhitsathian $S$, Boonyanaruthee $V$, et al: Metabolic syndrome in Thai schizophrenic patients: a naturalistic one year follow-up study. BMC Psychiatry 2007, 23:7-14.

20. De Hert M, van Winkel R, Van Eyck D, Hanssens L, Wampers M, Scheen A Peuskens J: Prevalence of diabetes, metabolic syndrome and metabolic abnormalities in schizophrenia over the course of the illness: a cross-sectional study. Clin Prac Epidemiol Ment Health 2006, 2:14. doi:10.1186/1745-0179-2-14.

21. Troxel WM, Matthews KA, Gallo LC, Kuller LH: Marital quality and occurrence of the metabolic syndrome in women. Arch Int Med 2005, 165:1022-1027.
22. Lin CC, Liu CS, Lai MM, Li Cl, Chen CC, Chang PC, Lin WY, Lee YD, Li TC: Metabolic syndrome in a Taiwanese metropolitan adult population. BMC Publ Health 2007, 7:239. doi:10.1186/1471-2458-7-239.

23. Robson D, Gray R: Serious mental illness and physical health problems: a discussion paper. Int J Nurs Stud 2007, 44:457-466.

24. Hennekens $\mathrm{CH}$, Hennekens AR, Hollar D, et al: Schizophrenia and increased risks of cardiovascular disease. Am Heart J 2005, 150:1115-1121.

25. Hall MH, Muldoon MF, Jennings JR, Buysse DJ, Flory JD, Manuck SB: Self-reported sleep duration is associated with the metabolic syndrome in midlife adults. Sleep 2008, 31(5):635-643.

26. Lam JC, Ip M: Sleep \& the metabolic syndrome. Indian J Med Res 2010, 131:206-216.

27. Tschoner A, Engl J, Laimer M, Kaser S, Rettenbacher M, Fleischhacker W, Patsch J, Ebenbichler C: Metabolic side effects of antipsychotic medication. Int J Clin Pract 2007, 61(8):1356-1370.

28. Suvisaari JM, Saarni SI, Perälä J, et al: Metabolic syndrome among persons with schizophrenia and other psychotic disorders in a general population survey. J Clin Psychiatry 2007, 68:1045-1055.

doi:10.1186/1471-244X-13-87

Cite this article as: Bressington et al:: The prevalence of metabolic syndrome amongst patients with severe mental illness in the community in Hong Kong - a cross sectional study. BMC Psychiatry 2013 13:87.

\section{Submit your next manuscript to BioMed Central and take full advantage of:}

- Convenient online submission

- Thorough peer review

- No space constraints or color figure charges

- Immediate publication on acceptance

- Inclusion in PubMed, CAS, Scopus and Google Scholar

- Research which is freely available for redistribution 